\title{
Modeling rare gene variation to gain insight into the oldest biomarker in autism: construction of the serotonin transporter Gly56Ala knock-in mouse
}

\author{
Jeremy Veenstra-VanderWeele • Tammy N. Jessen • Brent J. Thompson • \\ Michelle Carter • Harish C. Prasad • Jennifer A. Steiner • James. S. Sutcliffe • \\ Randy D. Blakely
}

Received: 19 March 2009/Accepted: 25 May 2009/Published online: 9 June 2009

(C) Springer Science + Business Media, LLC 2009

\begin{abstract}
Alterations in peripheral and central indices of serotonin (5-hydroxytryptamine, 5-HT) production, storage and signaling have long been associated with autism. The 5-HT transporter gene (HTT, SERT, SLC6A4) has received considerable attention as a potential risk locus for autismspectrum disorders, as well as disorders with overlapping symptoms, including obsessive-compulsive disorder (OCD). Here, we review our efforts to characterize rare, nonsynonymous polymorphisms in SERT derived from multiplex pedigrees carrying diagnoses of autism and OCD and present the initial stages of our effort to model one of these variants, Gly56Ala, in vivo. We generated a targeting vector to produce the Gly56Ala substitution in the Slc6a4 locus by homologous recombination. Following removal of a neomycin resistance selection cassette, animals exhibiting germline transmission of the Ala56 variant were bred to
\end{abstract}

\footnotetext{
J. Veenstra-VanderWeele $\cdot$ M. Carter $\cdot$ R. D. Blakely

Departments of Psychiatry,

Vanderbilt University School of Medicine,

Nashville, TN 37232-8548, USA

T. N. Jessen • B. J. Thompson • H. C. Prasad • J. A. Steiner •

R. D. Blakely

Departments of Pharmacology,

Vanderbilt University School of Medicine,

Nashville, TN 37232-8548, USA

J. S. Sutcliffe

Departments of Molecular Physiology \& Biophysics,

Vanderbilt University School of Medicine,

Nashville, TN 37232-8548, USA

J. Veenstra-VanderWeele $\cdot$ J. S. Sutcliffe $\cdot$ R. D. Blakely $(\bowtie)$

Center for Molecular Neuroscience,

Vanderbilt University School of Medicine,

Nashville, TN 37232-8548, USA

e-mail: randy.blakely@vanderbilt.edu
}

establish a breeding colony on a 129S6 background, suitable for initial evaluation of biochemical, physiological and behavioral alterations relative to SERT Gly56 (wildtype) animals. SERT Ala56 mice were achieved and exhibit a normal pattern of transmission. The initial growth and gross morphology of these animals is comparable to wildtype littermate controls. The SERT Ala56 variant can be propagated in 129S6 mice without apparent disruption of fertility and growth. We discuss both the opportunities and challenges that await the physiological/behavioral analysis of Gly56Ala transgenic mice, with particular reference to modeling autism-associated traits.

Keywords Serotonin - Transporter Polymorphism .

Transgenic mouse $\cdot$ Protein kinase G · p38 mitogen activated protein kinase $\cdot$ Autism

\section{Introduction}

The serotonin system is implicated in autism

Elevated whole blood serotonin (5-hydroxytryptamine, 5HT) was first reported in autism by the lab of Daniel X. Freedman in 1961 [1], well before 5-HT was fully accepted as a neurotransmitter [2]. Serotonin was discovered as a serum factor leading to vasoconstriction in 1948 by Maurice Rapport and colleagues [3]. This work converged with that of Vittorio Erspaner, who identified in 1952 that 5-HT was the agent secreted by enterochromaffin cells previously designated as 'enteramine' [4]. Subsequent work demonstrated that 5-HT synthesized in enterochromaffin cells is released into the enteric circulation and taken up by platelets, which contain more than $99 \%$ of the 5 -HT in 
peripheral blood [5]. Due to the vastly greater amount of 5HT contained in platelets, it is challenging to measure free 5-HT in plasma, and it is unclear if plasma 5-HT levels are changed in autism $[6,7]$. Thus, hyperserotonemia appears to arise from elevated platelet stores of 5-HT.

Nearly fifty years have passed since the initial description of whole blood 5-HT as a biomarker in autism, described sixteen years earlier by Leo Kanner [8]. Subsequent studies have repeatedly demonstrated that more than one-quarter of autistic children are found to have elevated whole blood 5HT levels [9], and, indeed, hyperserotonemia is arguably the most highly reproduced biomarker linked to a neurobehavioral disorder. A recent study in a more homogeneous Dutch population suggests that whole blood 5-HT may actually show a bimodal distribution in autism [10]. Despite the long-standing observation of hyperserotonemia in autism, our understanding of its origin and relationship to the etiology of autism remains incomplete.

Functional studies of the platelet serotonin system in autism have evaluated both the serotonin transporter and serotonin receptors. The 5-HT transporter (5HTT, SERT) is essential for the uptake of the biogenic amine into the platelet. Some but not all studies indicate alterations in platelet 5-HT uptake as well as SERT binding levels in autism [11-19]. Some studies have also shown decreased platelet serotonin receptor $5-\mathrm{HT}_{2}$ binding [20-22], which could possibly influence platelet 5 -HT levels by modulation of platelet activation and release. Of note, recent work from our laboratory indicates that the $5-\mathrm{HT}_{2 \mathrm{~A}}$ receptor can modulate SERT associations with the platelet membrane skeleton [23]. Inconsistency in transporter and receptor studies in autism likely reflects the complex regulatory systems that control platelet 5-HT utilization as well as platelet activation. Certainly, an important consideration is the regulation of gut production of 5-HT and its regulation by intrinsic signaling and transport mechanisms [24-28].

The robustness of hyperserotonemia as an autism biomarker has helped focus research on the genetic control of platelet 5-HT levels, with the belief that common regulatory mechanisms in the platelet and the central nervous system could reveal genes important to autism susceptibility. Indeed, one small study found higher whole blood 5-HT levels in children with ASD who had an affected sibling than in children with ASD but no affected siblings [29]. In the Hutterites, a large founder population not ascertained for brain disorders, whole blood 5-HT levels were found to be under nearly complete genetic control, with a heritability of 0.99 [30]. In a small twin study, the maximum rate of 5-HT uptake was also found to be highly heritable [31]. The Cook lab has used linkage and association to map quantitative trait loci for whole blood 5-HT levels in the Hutterites [32]. The initial study found significant association at a functional polymorphism in the integrin $\beta 3$ subunit gene (ITGB3) as well as suggestive association at the Vitamin $\mathrm{D}$ receptor gene [32]. Follow-up analyses revealed that $I T G B 3$, as well as the 5-HT transporter gene (SLC6A4), were primarily associated with whole blood 5-HT levels in males [33]. Carneiro and colleagues subsequently demonstrated physical and functional interactions between the ITGB3 and SERT proteins that regulates both platelet 5-HT uptake and aggregation [26]. Consistent with these findings, three studies have now reported a gene-gene interaction between ITGB3 and SLC6A4 in association with autism [3436], supporting the idea that whole blood 5-HT represents a genetically-determined, intermediate phenotype in autism that can be mined for elucidation of disease susceptibility genes.

Recent data support the idea that the 5-HT system is also altered in the brain in autism. If the peripheral findings translate into the brain, increased 5-HT uptake or storage in the presynaptic terminal would be expected to diminish extracellular 5-HT availability. Unfortunately, a direct assessment of synaptic 5-HT in patients with autism is not possible with present technologies. A surrogate measure is the assessment of brain 5-HT synthesis, and indeed this measure demonstrates an altered developmental pattern in autism [37]. Other studies have evaluated 5-HT receptor binding. Two neuroimaging studies have found decreased $5-\mathrm{HT}_{2}$ receptor binding, one a SPECT study in adults with Asperger's syndrome [38] and the second a PET study in parents of children with autism [39]. Blatt's group has also presented data demonstrating decreased $5-\mathrm{HT}_{2 \mathrm{~A}}$ binding in post-mortem samples from autism subjects [40]. The overall consistent findings of decreased $5-\mathrm{HT}_{2}$ receptor binding in platelet, neuroimaging, and post-mortem studies supports the hypothesis that peripheral alterations in 5-HT systems contribute to the behavioral abnormalities associated with autism.

Finally, limited pharmacology studies underscore a role for the 5-HT system in autism. Dietary depletion of the 5HT precursor tryptophan, which is expected to cause decreased synaptic 5-HT, leads to worsened repetitive behaviors and irritability in autism [41]. Consistent with these findings, several studies have reported that 5-HT reuptake inhibitors can relieve symptoms of irritability and rigid-compulsive behavior in autism [42, 43]; more recent data from clinical trials are less supportive, but the wide spectrum of autism traits complicates selection of appropriate target symptoms in these trials. More consistent data supports the use of risperidone [44, 45], an atypical antipsychotic with antagonism at multiple monoamine receptors, including the $5-\mathrm{HT}_{2 \mathrm{~A}}$ receptor. It is striking that this agent has clinical utility in autism despite findings of reductions in $5-\mathrm{HT}_{2 \mathrm{~A}}$ receptor levels. This discrepancy 
may be an important clue that a primary effect impacting $5-\mathrm{HT}_{2 \mathrm{~A}}$ receptor sensitivity in these subjects may exist which may then trigger compensatory receptor downregulation.

Rare variants offer one way to approach complexity at the SERT gene

Multiple lines of evidence favor involvement of the 5-HT transporter gene (SLC6A4) in autism; although the cumulative data are not straightforward or uniform in their support, which is perhaps not surprising in a complex behavioral disorder with a polygenic origin. Most of this evidence has emerged from candidate gene studies oriented around the platelet 5-HT system. Importantly, linkage studies have also implicated the chromosome 17q11-q21 region containing SLC6A4 [46, 47]. Follow-up linkage studies [48-50] have detected more significant evidence for linkage in this region when considering families with two or more affected male children and no affected females. These findings suggest that SERT might harbor sex-specific risk alleles for autism and possibly contribute to, or be responsive to, the gender bias of autism. Such an idea is in line with the findings that variation in SLC6A4 is primarily associated with whole blood 5-HT levels in males [33]. It also matches accumulating evidence in the 5-HT transporter knockout mouse that altered expression of SLC6A4 has sexually dimorphic effects on brain 5-HT systems and resulting behavior (reviewed in [51]).

With the accumulated evidence of alterations in the platelet 5-HT system in autism, it is not surprising that some of the earliest candidate gene association studies in autism focused on the SERT gene. Unfortunately, studies of SLC6A4 in autism have been complicated by the presence of multiple common functional variants in gene regulatory regions. The best-studied of these variants, the promoter length polymorphic repeat (5-HTTLPR) [52], was initially reported as associated with autism in haplotype analyses by the Cook lab [53]. Subsequent studies have yielded inconsistent findings. Indeed, although most studies have reported association with the short allele, which leads to less gene transcription, others have reported association with the long allele (reviewed in a recent meta-analysis [54]). Genotyping errors could possibly account for some of this inconsistency given deviation from Hardy-Weinberg equilibrium in some samples and discrepancies in genotypes of the same samples across different laboratories [55].

Other studies have explored the possible involvement of SLC6A4 in autism by expanding the range of polymorphisms studied. Indeed, multiple, additional functional polymorphisms have been discovered within the SLC6A4 gene regulatory regions [56-58], including a single nucleotide polymorphism (SNP) that reduces the functional impact of the 5-HTTLPR long allele ( $\mathrm{La}, \mathrm{Lg}$ ) [57]. To date, these polymorphisms have not been systematically studied in large autism samples. Other SLC6A4 polymorphisms and haplotypes that have been reported to associate with autism have not been fully characterized for either their own functional significance or linkage disequilibrium with other possible functional variants $[59,60]$. Indeed, one haplotype in linkage disequilibrium with the 5-HTTLPR short allele, which leads to decreased SERT expression, has actually been associated with increased platelet 5-HT uptake [61]. These findings signify a still incomplete understanding of SERT genetic regulation. A comprehensive analysis focusing on the impact of multiple alleles on predicted SERT expression or function should greatly enhance our understanding of the SERTserotonin-autism connection.

Another fruitful approach to understanding the possible involvement of SLC6A4 in autism susceptibility is to focus on either specific symptom clusters or on intermediate phenotypes. Four studies have reported association at various SLC6A4 polymorphisms when performing subanalyses of repetitive behavior in autism $[49,60,62,63]$. One of these studies also reported association of the 5HTTLPR short allele with poor non-verbal communication [63]. Two studies have reported association of various SLC6A4 polymorphisms with either whole blood 5-HT [64] or with 5-HT uptake in autism [61]. Finally, one study reported association of the 5-HTTLPR short allele with increased cortical gray matter in two- to four-year-old children with autism [65]. These collected studies of subphenotypes or intermediate phenotypes add strength to the hypothesis that $S L C 6 A 4$ represents a susceptibility gene for subgroups of children with autism.

One intriguing possibility to emerge from the data on common SLC6A4 variants is that optimal SERT activity is likely to be highly constrained, with both high and low SERT activity impacting autism susceptibility, though likely with different patterns of symptoms and intermediate phenotypes. Such an idea parallels ideas emerging from recent findings at the $M E C P 2$ gene implicated in Rett syndrome [66]. Additionally, this idea fits with the observation that genetic variation can lead to increased SERT function in association with repetitive behavior in autism [32, 46], as well as with OCD [56, 57, 67]; whereas genetic variation that supports decreased SERT function is associated with impaired social behavior [63] and increased cortical size in young children with autism [65], as well as in a mouse model of PTEN-associated autism [68].

Association of human SERT gene variants with autism traits

Despite intriguing findings of both common and rare functional SLC6A4 variants, the collective evidence does 
not come close to explaining the strong linkage findings in male sibling pairs in this chromosomal region [48-50]. Indeed, the collected evidence suggests that no single, common functional polymorphism at this locus underlies autism susceptibility, at least when considered individually. Recently, the Blakely and Sutcliffe labs explored the alternative hypothesis that multiple, rare functional variants account for some of the findings of linkage in this region. In a comprehensive analysis of SERT noncoding and coding exons from 120 families that contributed most to linkage at $17 \mathrm{q} 11.2$, our groups found 5 coding substitutions and 15 variants in $5^{\prime}$ noncoding and intronic regions transmitted in families [49]. In the aggregate, these variants showed significant association to autism and tracked specifically with rigid-compulsive traits.

In the initial study, one of the autism-associated variants, Gly56Ala, showed constitutively elevated SERT activity that was not further up-regulated through the PKG and p38 MAPK pathways in transformed lymphoblasts from autism probands [49]. This polymorphism, at an amino acid that is conserved across all mammalian SERTs, was the only SERT variant frequent enough to attempt independent statistical analyses, which revealed that the Ala56 allele: 1) was overtransmitted $3: 1$ to subjects with autism $(P=$ $0.025), 2)$ displayed a gender-bias (males) when considering affected subjects within linked pedigrees $(P=0.017)$, and 3) was associated with Autism Diagnostic Interview component factors corresponding to rigid-compulsive traits $(P=0.0085)$ and sensory aversion $(P=0.0005)$. The SERT amino-terminus where Gly56 resides is an important regulatory area [69-71]. These considerations make the Gly56Ala allele an important allele to model for system level effects in an animal model (see below).

Two of the SERT coding variants found in autism subjects in our studies, Gly56Ala and Lys605Asn, were both shown to exhibit a gain of function despite normal surface expression [72]. Our autism studies uncovered three additional SERT coding variants: Ile425Leu, Phe465Leu and Leu550Val. All three variants occur within transmembrane domains at amino acids that are highly conserved [49]. Rigid-compulsive behaviors were associated with these three novel SERT variants when analyzed as a group $(P=0.0003)$ [49]. When all linked families with individuals carrying a coding variant were considered together, the significance in elevated severity of rigid-compulsive behaviors increased $(P=0.0006)$.

Even these rare variants are unlikely to present a simple story given the presence in the SERT gene of multiple common functional variants that can affect gene expression. It is entirely possible that the functional effects of these rare variants, particularly the more subtle increased activity and dysregulation of Gly56Ala, could be partially offset in some individuals by common variants leading to decreased SERT expression or variation in other genes within 5-HT signaling networks. Indeed, one subsequent study did not find association of rare SERT variants with autism or rigidcompulsive behavior in families without evidence for linkage to this region [73]. Another study did not find association of the Ala56 allele when considered alone in OCD [74]; although it is quite possible that these seemingly related disorders arise from distinct origins. Regardless, the discovery of functional amino acid variants in SERT offers a critical opportunity to translate altered SERT activity into an animal model for comprehensive assessment of genotype/ phenotype assessments beyond what is feasible in humans.

In vitro analysis of autism-associated SERT coding variants

Of the five coding variants that we identified in probands from multiplex autism families, two of these, Gly56Ala and Lys605Asn, were actually first characterized, along with eight other rare SERT variants, independent of their potential roles in autism [72, 75]. In comparison to the reference hSERT cDNA (often termed "wild-type") originally identified by Ramamoorthy and colleagues [76], both Ala56 and Asn605 demonstrated elevated 5-HT transport activity in transfected HeLa cells [72]. This gain-offunction transport property was shared (and even exceeded) by several other SERT coding variants including Ile425Val, a variant reported by Ozaki and colleagues in association with two pedigrees bearing a complex neuropsychiatric phenotype including OCD, autism spectrum disorder, social phobia, and alcohol abuse [77]. Since these studies, additional cases of Val425 in OCD have been reported [78]. Clearly, the identification of two mutations at the same site (Val425 vs Leu425) in disorders with trait overlap increases the probability that both are functional and relevant to disease status.

Recently, we described the functional properties of Leu425, Leu465 and Val550, expressed in HeLa cells in parallel with Ala56 and wildtype human SERT [79]. These studies (Fig. 1) revealed for the first time that all autismassociated SERT coding variants confer a gain-of-function phenotype. Kinetic studies provided the first evidence, however, that the elevated SERT activities of these variants arise from distinct mechanisms. Thus, Ala56 displays a reduction in 5-HT $\mathrm{K}_{\mathrm{M}}$, consistent with a shift to a highaffinity state for 5-HT, whereas the other three variants display elevated $\mathrm{V}_{\mathrm{MAX}}$ and no change in $\mathrm{K}_{\mathrm{M}}$ (Table 1). $\mathrm{V}_{\mathrm{MAX}}$ increases in transport kinetic studies are typically associated with changes in the number of transporter molecules expressed at the cell surface, though other explanations are possible. Interestingly, Kilic and colleagues reported that Ile425Val exhibits a $\mathrm{K}_{\mathrm{M}}$ shift with no change in $\mathrm{V}_{\mathrm{MAX}}$. As we have discussed elsewhere [71], the Kilic studies utilized an overexpression system (COS 


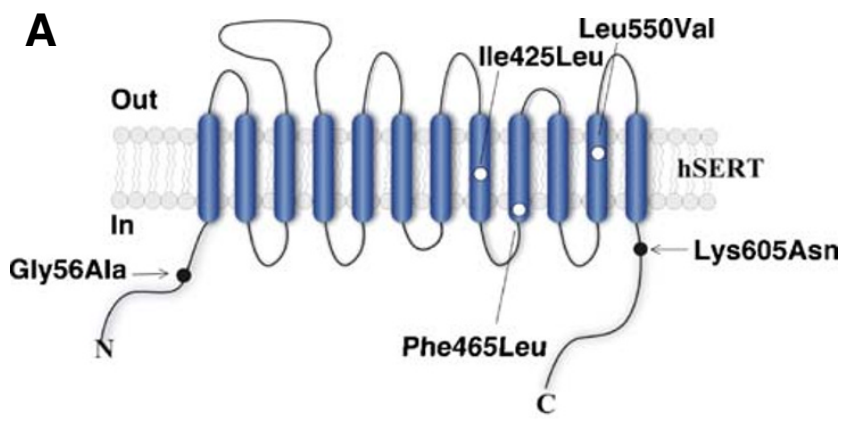

B

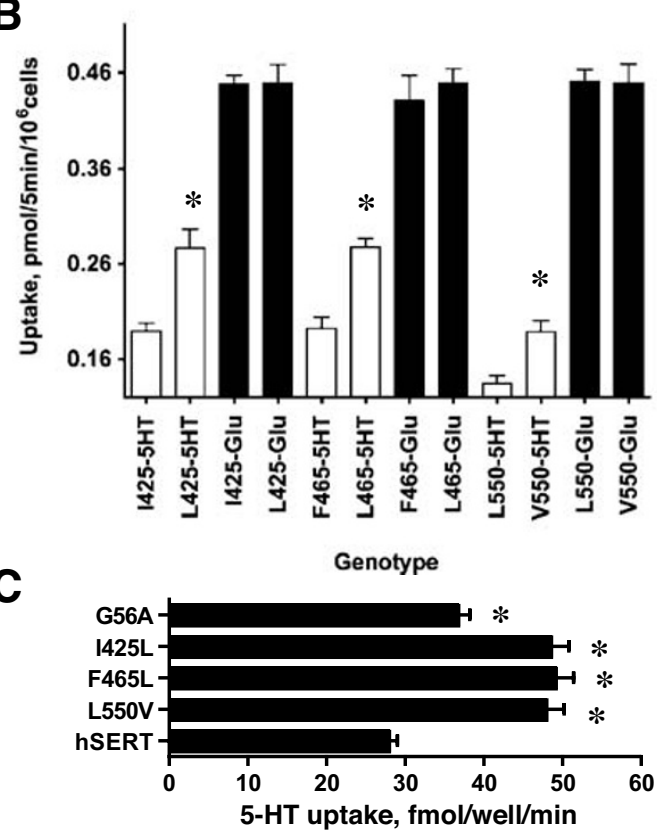

Fig. 1 Location and 5-HT transport activity of autism-associated SERT coding variants. A) Autism-associated variants are overlayed on a 12 TM model of a single SERT subunit, with $\mathrm{NH} 2$ and $\mathrm{COOH}$ termini oriented inside the cell. Variants in extramembrane domains are shaded black whereas those in membrane domains are shaded white. B) Altered activity of SERT variants is evident in native lymphocytes. Lymphocytes were genotyped and cultured and assessed for 5-HT uptake. Data presented derive from $n=3$ individual assays on lymphocyte lines of determined genotype. Findings were replicated in a separate set of pre-genotyped samples with equivalent results. Transport activities were analyzed by a One-Way ANOVA with posthoc Dunnett's tests, with $p<0.05(*)$ taken as significant. C) 5-HT transport activity of autism-associated SERT coding variants in transfected HeLa cells. All variants were transfected in parallel with reference hSERT cDNA into HeLa cells and assayed for 5-HT transport activity. Data reflect mean values \pm SEM of 3 separate experiments. Means were compared to hSERT cDNA using a OneWay ANOVA followed by Dunnett's test of individual means against hSERT values with $p<0.05(*)$ taken as significant. Figure reproduced from authors' prior work [79]

cells), whereas we expressed SERT constructs at levels comparable to that seen in natively expressing cell lines (e.g. RBL-2H3, RN46A). Possibly, the high expression levels of the COS overexpression system preclude detection of Vmax changes whereas a trafficking impact in our HeLa model might somehow mask $\mathrm{K}_{\mathrm{M}}$ effects, though they are detectible for Gly56Ala and Lys605Asn.

In part due to the discrepancies with kinetic analyses noted above, we performed surface binding and biotinylation studies on all autism-associated SERT variants [79]. These studies reveal that all variants exhibit comparable total $\left[{ }^{125}\right.$ I]RTI-55 binding, compatible with evidence of equivalent protein expression as detected by Western blots (Fig. 2). In contrast, differences in $\left[{ }^{125} \mathrm{I}\right] \mathrm{RTI}-55$ surface expression were evident between Gly56Ala and the other SERT coding variants, findings verified in surface protein biotinylation studies. Whereas surface Gly56Ala levels were equivalent to, or lower than that found for wildtype SERT, surface expression of Leu425, Leu465 and Val550 were significantly elevated. These data indicate that the increase in uptake activity for Ala56 in transiently-transfected HeLa cells comes about from catalytic activation, whereas the increases in uptake for Leu425, Leu465 and Val550 arise from enhanced surface expression. Whether the latter effects arise from elevated insertion of transporters, reduced endocytosis or enhanced recycling after endocytosis is not known but presently under evaluation.

A striking feature of the Ala56 variant (and Asn605) observed in our initial characterization of deposited SERT variants [72] is its lack of responsiveness to two protein kinases previously shown to influence SERT surface expression [80] (protein kinase G, PKG) and catalytic activation [80] (p38 mitogen activated protein kinase, p38 MAPK). These observations compelled us to evaluate all autism-associated SERT coding variants for their ability to support acute regulation by these kinases. As before, Ala56 was insensitive to activators of either PKG or p38 MAPK (Fig. 3). In contrast, stimulation of these kinases produced significant increases in activity for Leu425, Leu465 and Val550, though slightly lower than that observed for wildtype SERT. Regardless, these observations support the presence of two distinct classes of functional perturbations for these variants. Similar distinctions were also evident with protein kinase $\mathrm{C}$ regulation, where enhanced sensitivity is evident for Ala56 but not for Leu425, Leu465 and Val550. The Ser/Thr protein phosphatase 2A (PP2A) has been implicated in SERT regulation and forms a reversible physical complex with the transporter [81]. Although PKC, PKG and p38 MAPK activators distinguish among SERT variants, PP2A antagonist sensitivity appears to be lost for both Ala56 and Leu425, two variants that represent the two distinct classes of regulatory defects observed in SERT variants. These findings indicate that altered PP2A interactions or SERT dephosphorylation may be a more fundamental alteration that extends across all variants, with secondary effects linked to the physical site of mutations. Additional studies are needed to localize the site(s) of interaction of PP2A with SERT, as well as the sites of SERT 
Table 1 Rare serotonin transporter coding variants identified in autism and autism spectrum (Jeremy)

\begin{tabular}{lll}
\hline SERT variant & Location & Effect on Function \\
\hline Gly56Ala [49] & N-terminal intracellular tail & $\sim 30 \%$ increase in 5-HT uptake; absent upregulation by PKG, p38-MAPK [72, 79] \\
Ile425Leu [49] & Transmembrane domain & $\sim 70 \%$ increase in 5-HT uptake; increased cell surface expression [79] \\
Ile425Val [77] & Transmembrane domain & $\sim 70 \%$ increase in 5-HT uptake; increased cell surface expression vs. altered \\
& & PKG regulation [79, 94] \\
Phe465Leu [49] & Transmembrane domain & $\sim 70 \%$ increase in 5-HT uptake; increased cell surface expression [79] \\
Leu550Val [49] & Transmembrane domain & $\sim 70 \%$ increase in 5-HT uptake; increased cell surface expression [79] \\
Lys605Asn [49] & C-terminal intracellular tail & $\sim 30 \%$ increase in 5-HT uptake [72] \\
\hline
\end{tabular}

A

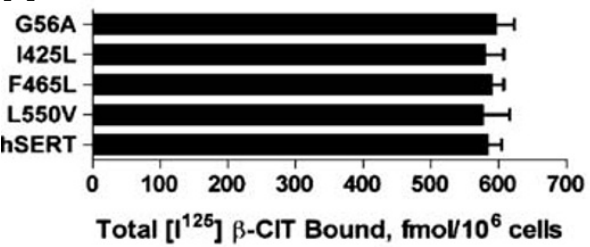

C

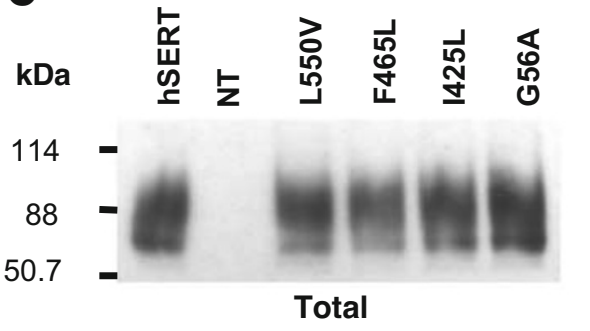

E

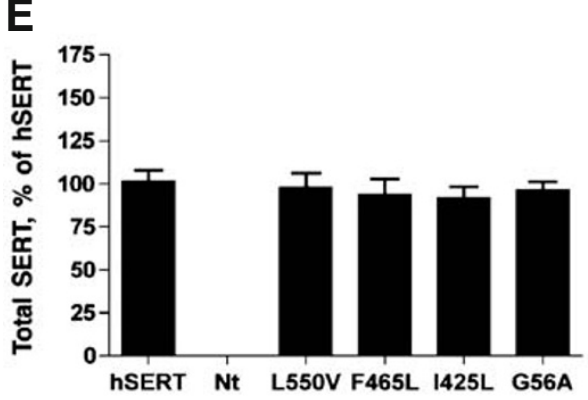

Fig. 2 Analysis of protein expression of autism-associated SERT coding variants. Impact of SERT coding variants on total and cell surface $\left[{ }^{125}\right.$ I]RTI-55 binding. HeLa cells transiently transfected with hSERT or one of the SERT coding variants were subjected to intact cell binding assays at $4{ }^{\circ} \mathrm{C}$ with the cocaine analog $\left[{ }^{125} \mathrm{I}\right] \mathrm{RTI}-55$ $(5 \mathrm{nM})$. A) Total binding values as defined with paroxetine $(10 \mu \mathrm{M})$ as displacer. B) Surface labeling by $\left[{ }^{125}\right.$ I]RTI-55 as defined with 5-HT $(100 \mu \mathrm{M})$ as displacer. In vehicle-treated cells, hSERT total binding $\left(\mathrm{fmol} / 10^{5}\right.$ ) was $583.7 \pm 20.6$, and the surface binding was $175.7 \pm 11.7$. Results for A) and B) reflect mean values \pm SEM of three separate experiments normalized to hSERT $(100 \%)$. Binding levels were analyzed via a One-Way ANOVA followed by post-hoc Dunnett's tests comparing mutant means to hSERT, with $p<0.05(*)$ taken as significant. C) Immunoblots of total cell extracts prepared from HeLa
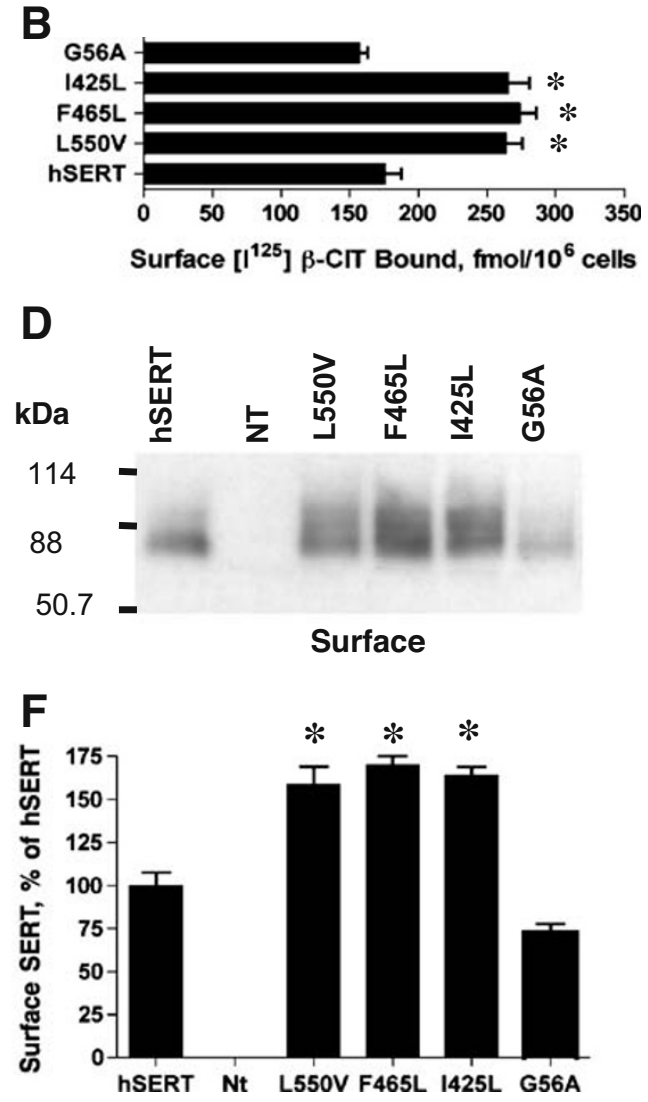

cells transfected with hSERT or one of the variants described in the study. D) Cell surface expression alterations in hSERT Gly56Ala, Ile425Leu, Phe465Leu and Leu550Val. Variants were transfected in parallel with hSERT into HeLa cells and cell surface transporters identified by immunoblotting of biotinylated samples. Quantitative estimations of relative E) total and F) surface density of hSERT, Gly56Ala, Ile425Leu, Phe465Leu and Leu550Val based on densitometry of biotinylation immunoblots. Data reflect mean values of three separate experiments \pm SEM. Means were compared with a One-Way ANOVA followed by Dunnett's test to compare variant surface expression to that achieved with hSERT, with $p<0.05$ taken as significant (* Significantly elevated vs hSERT, $p<0.05$; \# Significantly reduced vs hSERT, $p<0.05)$. Figure reproduced from authors' prior work [79] 

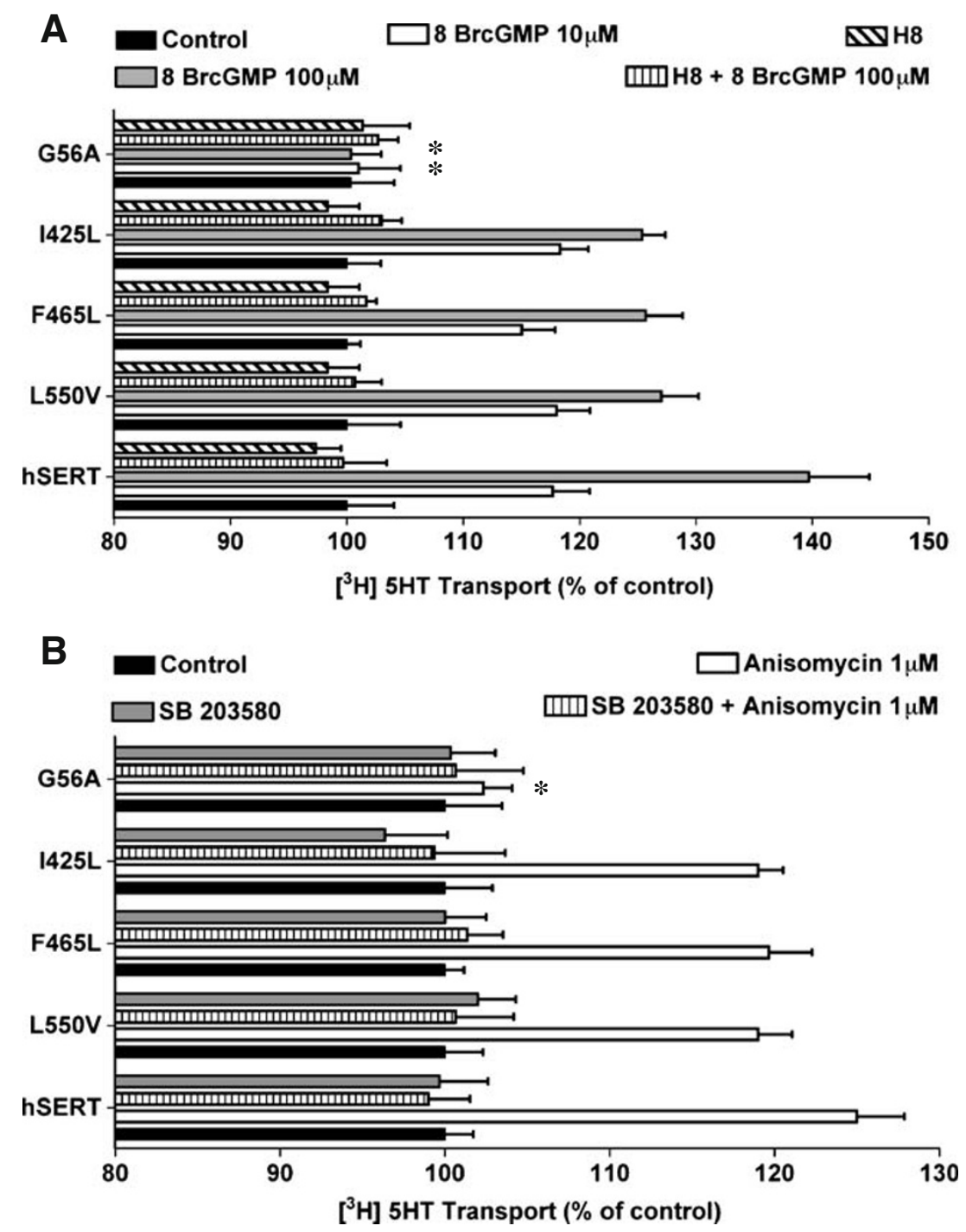

Fig. 3 Impact of 8BrcGMP and p38 MAPK on SERT activity of autism-associated hSERT coding variants. A) Activity modulation. HeLa cells transfected with hSERT or autism-associated hSERT coding variants were examined for 5-HT transport activities following pretreatments of cells with either $100 \mu \mathrm{M} 8 \mathrm{BrcGMP}$ or vehicle for $1 \mathrm{hr}$. Parallel wells were treated with the PKG inhibitor H8 $(10 \mu \mathrm{M})$ to validate specificity. B) Altered p38 MAPK-dependent regulation of hSERT in transfected HeLa cells. Cells transfected with hSERT or autism-associated hSERT coding variants were examined for 5-HT transport activities following pretreatments of cells with either $1 \mu \mathrm{M}$ anisomycin or vehicle for $10 \mathrm{~min}$. Parallel wells were treated with the p38 MAPK inhibitor SB203580 $(1 \mu \mathrm{M})$ to validate specificity. Results reflect mean values \pm SEM of three separate experiments normalized to each mutant's control measured under vehicle treated conditions $(100 \%)$. Results in A and B reflect mean values \pm SEM of three separate experiments normalized to each mutant's level under vehicle treated conditions (100\%). Data were analyzed by a One-Way ANOVA with post-hoc Bonferonni tests comparing variant to hSERT 8BrcGMP/anisomycin responses with $p<0.05$ taken as significant. Figure reproduced from authors' prior work [79] phosphorylation relevant to PP2A action, further clarifying the mechanism of loss of PP2A sensitivity.

The studies reviewed above for altered SERT regulation in autism-associated coding variants derive from transiently-transfected cells. In an attempt to generate a stable model for SERT variants, where expression is driven from the same genomic locus, we produced stable cell lines with the wildtype SERT, Ala56 and Leu425 using the CHO-Flp-In model. Surprisingly, 5-HT transport assays and
Western blots of $\mathrm{CHO}$ cell extracts revealed a significant reduction in SERT activity and expression for both SERT Ala56Ala and Leu425 compared to hSERT (Fig. 4). Our current hypothesis for this effect is that it is a result of growth suppression and cell death that arises with elevated 5-HT accumulation in cells that do not have a vesicular storage compartment for the amine. Although this finding may appear to be a symptom of heterologous expression, we recognize that SERT is expressed in contexts without such 


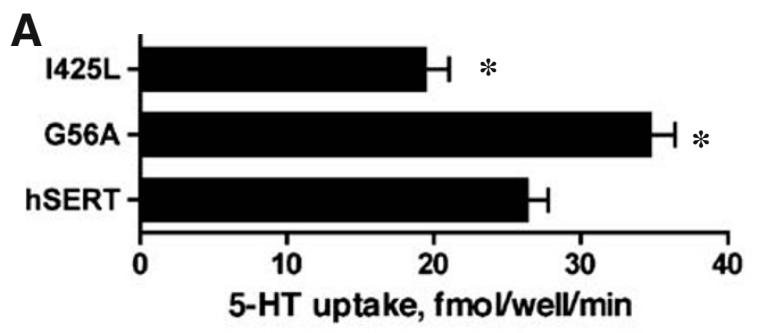

B

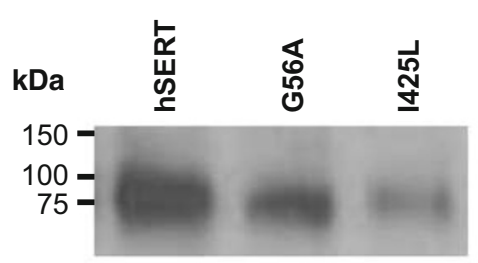

D

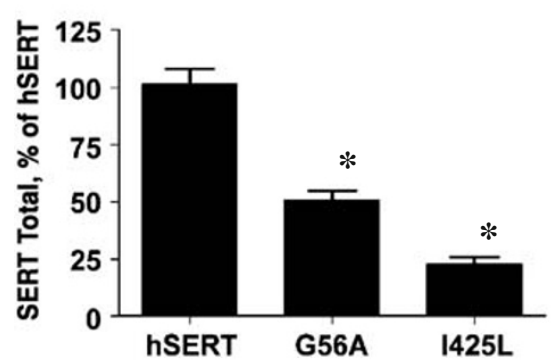

$\mathbf{F}$

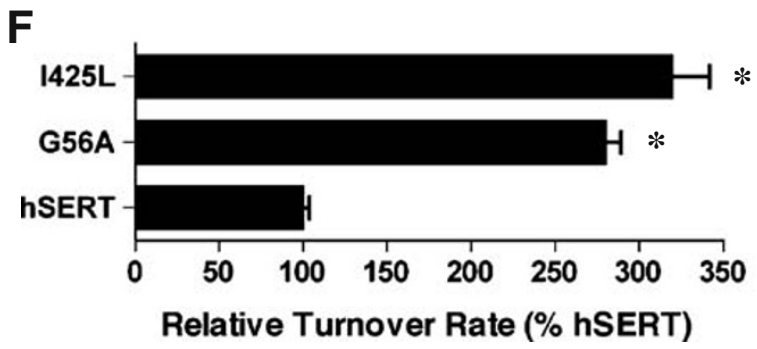

C

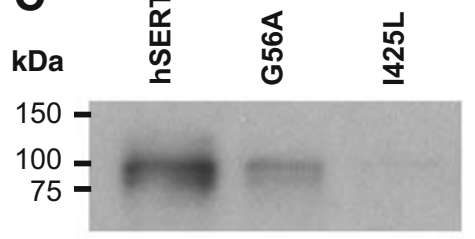

E

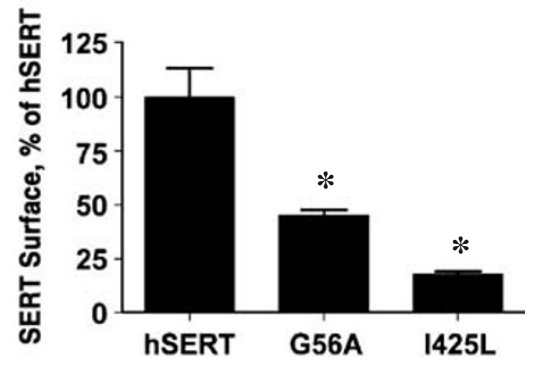

Fig. 4 Altered activity of SERT variants is differently exhibited in CHO-Flip-In ${ }^{\mathrm{TM}}$ stable cells. A) 5-HT transport activity of autismassociated SERT coding variants in CHO-Flip- $\mathrm{In}^{\mathrm{TM}}$ stable cells. All variants were assayed for 5-HT transport activity. Data reflect mean values \pm SEM of 3 separate experiments. Means for variants were compared to hSERT using a One-Way ANOVA followed by Dunnett's test of individual means against hSERT values with $p<0.05(*)$ taken as significant. B) Immunoblots of total cell extracts prepared from CHO-Flip-In ${ }^{\mathrm{TM}}$ stable cells expressing hSERT or one of the variants described in the study. C) Cell surface expression alterations in hSERT, Gly56Ala, and Ile425Leu. Cell surface transporters were identified by immunoblotting of biotinylated samples. Quantitative

vesicular compartments, raising the possibility that alterations in cell growth and viability arise as a consequence of heightened SERT expression and contribute in unexpected ways to the complex phenotypes observed in autism. Despite these basal effects on expression, we were able to use this model to investigate changes in catalytic rates. In the CHOFlp-In model, when functional activity is normalized by surface expression, a significant catalytic activation is estimations of relative D) total and E) surface density of hSERT, Gly56Ala, and Ile425Leu based on densitometry of biotinylation immunoblots. Data reflect mean values of three separate experiments \pm SEM. Means were compared with a One-Way ANOVA followed by Dunnett's test to compare variant surface expression to that achieved with hSERT, with $p<.05$ taken as significant. F) Gly56Ala and Ile425leu proteins exhibit enhanced catalytic function, with a turnover rate of $\sim 250 \%$ or more than that of wildtype SERT. Data reflect mean values of three separate experiments \pm SEM. Means were compared with a One-Way ANOVA followed by Dunnett's test. Figure reproduced from authors' prior work [79]

evident for both Gly56Ala and Ile425Leu. Together, these findings suggest that heterologous expression systems provide important, but likely only partial windows on the impact of autism-associated SERT variants.

Ideally, one would like to evaluate the impact of SERT coding variants on the brain of autism subjects. While we hope to pursue this need with transgenic mice, it seems unlikely that such analyses in humans will be available in 
the near future. It is well known, however, that SERT is expressed in transformed lymphoblasts [52], the very same models used to archive DNA from subjects recruited for genetic studies. We took advantage of this opportunity to examine basal transport activity and regulation in cells derived from autism subjects. Indeed, Ala56 [79], as well as the other autism-associated SERT variants, display elevated 5-HT transport activity (Fig. 1). As a control in the latter studies, L-glutamate transport was found to be equivalent to that in wildtype SERT, consistent with alterations derived from a specific influence on SERT expression and/or regulation. Interestingly, although transformed lymphoblasts do not express a vesicular storage mechanism for 5HT (to our knowledge), SERT expression is low in these cells relative to platelet and raphe neurons, such that the growth perturbations noted above for stable CHO-Flp-In cells do not appear to reduce our ability to detect 5-HT transport enhancement. Studies with multiple lymphoblast lines expressing the Ala56 variant [49] also reveal that activators of PKG and p38 MAPK display the loss of kinase sensitivity seen with transfected HeLa cells. Together, these findings reinforce the properties of autismassociated SERT variants as gain-of-function mutants that also display complex regulatory deficits.

In vivo manipulations of the mouse SERT gene

A number of methods are available to manipulate genes in the mouse, including gene knockout, regional or inducible gene knockout, and transgenic overexpression, including inducible and reversible systems. The first knockout of the mouse SERT gene was performed by deletion of exon 2 in the labs of Dennis Murphy and Klaus-Peter Lesch [82]. Over two hundred papers have now been published describing this mouse's phenotype, which includes increased anxiety-like behavior, increased stress reactivity, decreased aggression, obesity, and disruption of brain architecture in the sensory cortex and amygdala (reviewed in [51]). Despite seeing decreased platelet 5-HT levels, the opposite of what is observed in the hyperserotonemia of autism, these mice also show decreased sociability in the Crawley test [83]. Interestingly, when bred with mice haploinsufficient for Pten, a putative autism susceptibility gene, SERT +/- knockout mice show an exacerbation of the macrocephaly and decreased sociability characteristic of the Pten $+/-$ mice [68]. These findings may be consistent with the idea that SERT activity may be constrained within a certain range, with elevated or diminished SERT function leading to vulnerability to autism-like behavior.

Another genetic manipulation was performed in a mouse line expressing a human SERT transgene generated in the lab of Trevor Sharp [84]. These mice show a 2- to 3-fold increase in SERT binding sites and a resulting decrease in extracellular 5-HT. Their platelet 5-HT levels have not yet been assessed. Providing a contrast to the SERT knockout mice, these hSERT transgenic overexpressing mice show a decrease in anxiety-like behavior that reverses with acute treatment with a 5-HT reuptake inhibitor. Furthermore, they show increased sensitivity to $5-\mathrm{HT}_{2}$ receptor stimulation [85], again in contrast to the SERT KO mice, which show decreased sensitivity [86]. This mouse could potentially serve as a surrogate model of the increased SERT function hypothesized in autism and OCD, but the use of a human SERT locus introduced using a yeast artificial chromosome construct may lead to alterations in gene regulation and expression patterns, as well as altered protein regulation and function, when introduced into the mouse.

Based upon our belief that manipulation of a native gene was likely to yield a meaningful brain and behavioral readout of increased SERT function, we chose to introduce a knock-in of the Ala56 allele into the native mouse SERT gene. We chose the Ala56 allele for three reasons: 1) it shows association with rigid-compulsive behavior and sensory aversion in autism; 2) it is the most common amino acid variant of human SERT; 3) it offers an opportunity to probe the importance of altered SERT regulation in vivo.

\section{Methods}

Production of mSERT Gly56Ala knock-in mouse

Approval was obtained from the Vanderbilt Institutional Animal Care and Use Committee for all experiments involving mice. A targeting construct was created containing exons 2-5 of the mouse 129S6 Slc6a4 gene with a floxed Neomycin-resistance cassette inserted between exons 4 and 5 (SERT Ala56-Neo, Fig. 5). This construct was electroporated into mouse 129S6 embryonic stem cells in the Vanderbilt University Transgenic Mouse / Embryonic Stem Cell Shared Resource facility. Correct targeting of the Ala56-Neo knock-in allele was identified by polymerase chain reaction screening (PCR) and confirmed by Southern blot. Embryonic stem cells containing the SERT Ala56-Neo knock-in allele were then microinjected into the blastocoel cavity of 3.5-day-old C57Bl/6 embryos, which were then transferred into the uterus of a pseudopregnant recipient animal. The resulting chimeric animals were bred with 129S6 female mice. Pups were screened by PCR for germline transmission of the SERT Ala56-Neo allele. Heterozygous Gly56Ala-Neo animals were then bred to a 129S4 protamine-Cre mouse line to allow germline excision of the SERT-56Ala-Neo floxed Neomycinresistance cassette [87]. The resulting SERT Gly56Ala pups were bred to generate a colony of mice including 
Fig. 5 Diagram for Knock-in of Gly56Ala allele in to Slc6a4 locus. The targeting vector with the Ala56 knock-in mutation contained a floxed positive selection Neomycin-resistance cassette and a negative selection thymidine kinase cassette. Recombination with 129S6 embryonic stem cell DNA resulted in an Slc6a4 gene containing the Ala56 knock-in mutation, as well as two loxP sites surrounding the Neomycin-resistance cassette in intron 4. Breeding with Protamine (Prm) Cre transgenic mice yielded excision of the floxed Neomycinresistance cassette with retention of a residual loxP site in intron 4

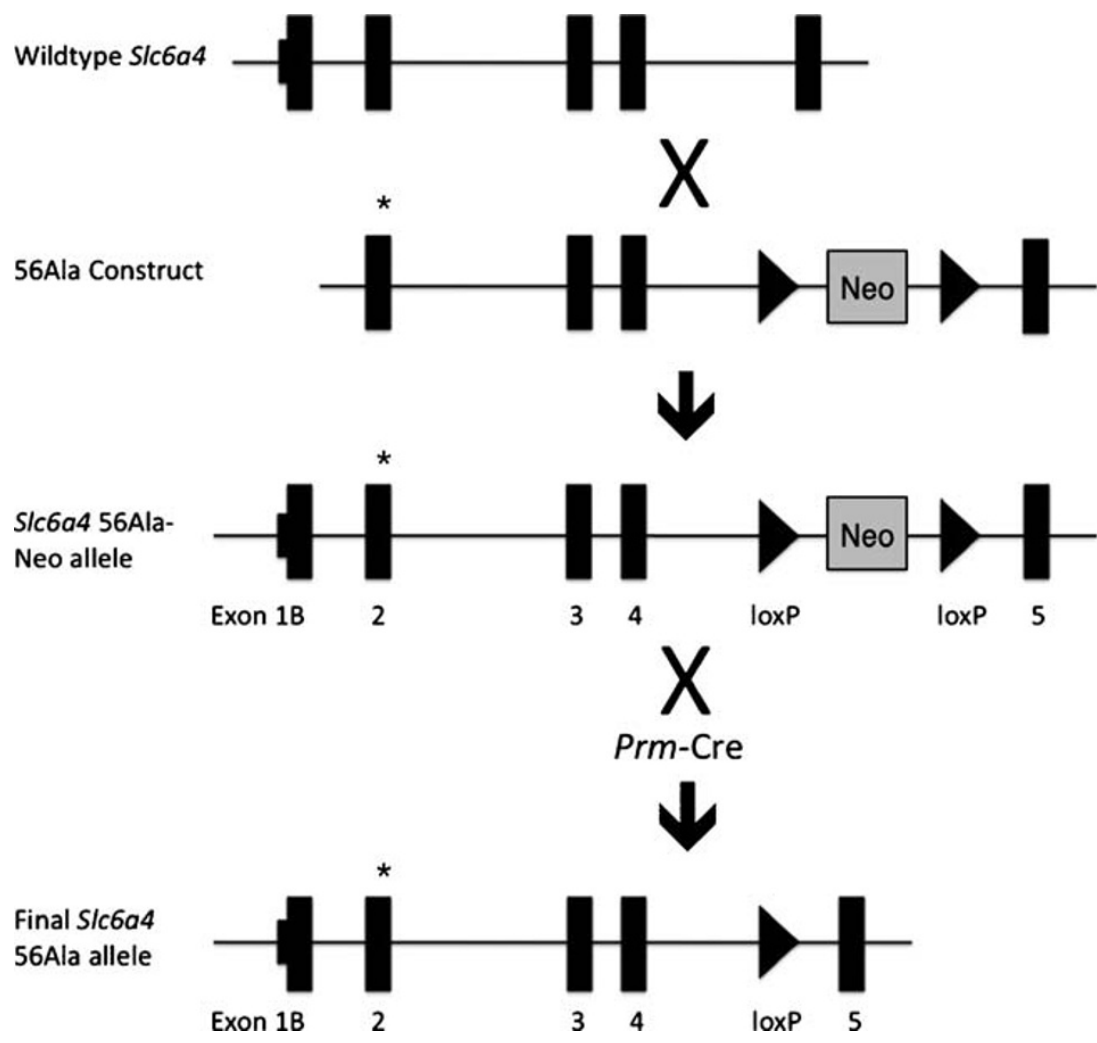

Ala/Ala knock-in mice and wildtype Gly/Gly littermate controls.

Genotyping and initial growth analysis of SERT Ala56 knock-in mice

At two weeks of age, a 3-5 mm section of tail was removed for DNA extraction using the Sigma REDExtract-N-Amp Tissue PCR Kit (Sigma-Aldrich, St. Louis, MO, http:// www.sigmaaldrich.com). Each PCR reaction contained $2 \mu \mathrm{L}$ of tail DNA extract, $5 \mu \mathrm{L}$ of Sigma REDExtract-NAmp PCR Reaction Mix, $0.5 \mu \mathrm{L}$ of each of the two $25-\mu \mathrm{M}$ primers (Sense 5'-cctggccctcttagcaggtt-3'; Antisense 5'aggaggagaagccagcaagg- $3^{\prime}$ ), and $2 \mu \mathrm{L}$ of water, for a $10-\mu \mathrm{L}$ total reaction volume. All of the PCR reactions were performed on an MJ Research DNA Engine PTC-200 thermocycler (Bio-Rad, Hercules, CA, http://www.bio-rad. com) under the following conditions: initial denaturation step of $94^{\circ} \mathrm{C}$ for $2 \mathrm{~min}$; followed by 5 cycles of three alternating steps $\left(94^{\circ} \mathrm{C}\right.$ for $30 \mathrm{sec}, 63^{\circ} \mathrm{C}$ for $45 \mathrm{sec}$, and $72^{\circ} \mathrm{C}$ for $\left.60 \mathrm{sec}\right)$; followed by 35 cycles of three alternating steps $\left(94^{\circ} \mathrm{C}\right.$ for $30 \mathrm{sec}, 61^{\circ} \mathrm{C}$ for $45 \mathrm{sec}$, and $72^{\circ} \mathrm{C}$ for $\left.60 \mathrm{sec}\right)$; followed by one final extension step of $72^{\circ} \mathrm{C}$ for $8 \mathrm{~min}$. Final PCR products were analyzed by horizontal gel electrophoresis in 1\% agarose (GenePure LE, ISC BioExpress, Kaysville, UT, http://www.bioexpress. com). The PCR product from the wildtype 129S6 SERT gene allele is $642 \mathrm{bp}$ long, and the PCR product from the mutant 129S6 SERT Ala56 allele is 752 bp long. The $\chi^{2}$ test was used to evaluate deviation from expected HardyWeinberg equilibrium allele frequencies.

Pups from SERT 56Gly/Ala heterozygote matings were weighed weekly from one week of age until eight weeks of age. Repeated Measures Analysis of Variance was used to evaluate sources of variation between mice of different genotypes over time.

\section{Results and discussion}

We have successfully introduced the SERT Ala56 allele into a 129S6 mouse background. Out of 308 embryonic stem cell lines that survived neomycin selection, a single ES line positive for the knock-in allele was selected for transfer to pseudopregnant females and chimera production. Eight chimeras with significant evidence of mosaicism were generated and animals with the greatest degree of 129S6 DNA, as assessed by coat color, were selected to analyze germ-line transmission, generating our founder animal and subsequent progeny. We then used Cre-based recombination to remove the neomycin-resistance cassette that often interferes with targeted gene expression. Heterozygous animals were bred to homozygosity on a 129S6 background and maintained this way except for initiation of backcrossing to C57BL/6J (ongoing). The initial 129S6 SERT Ala56 mice are viable and show a normal distribution of 
genotypes in their offspring (Table 2) (Test for deviation from Hardy-Weinberg equilibrium $\chi^{2}=0.14, p=0.93$ ). Their initial growth trajectory mirrors that of the wildtype animals (Repeated Measures ANOVA, Genotype $F=0.44, p=0.65$; Interaction $F=0.46, p=0.95$ ) (Fig. 6).

With the successful generation of both homozygous Ala/Ala mice as well as heterozygous carriers, our thoughts now turn to analyses that are predicted by trait associations in children possessing the variant, as well as biochemical and behavioral traits seen in autism more generally. Modeling the SERT Ala56 variant in transfected cells and in transformed cells has identified an intriguing phenotype of increased baseline activity and failure to further upregulate via the PKG and p38-MAPK pathways. In vivo modeling of this variant in a knock-in mouse will allow us to answer a number of questions, ranging from basic to translational. We will need to verify that mRNA and protein expression patterns resulting from the introduction of this knock-in allele will parallel native mouse SERT. We will want to establish that the SERT Ala56 in vitro phenotype of increased transport is recapitulated in the mouse, initially using synaptosome preparations or platelets and progressing to in vivo assays. We will also evaluate whether the biomarker of elevated platelet 5-HT is present in the SERT Ala56 mouse.

After initial studies establish the characteristics of the mouse SERT Ala56 variant in vivo, a number of intriguing questions await. Some of these questions correspond to establishing face validity for behavioral traits that map onto autism symptoms (reviewed in [88]). Will the SERT Ala56 mice show alterations in social behavior [89]? Will they show repetitive behavior, perseverative exploration, or deficits in reversal learning, paralleling the association of SERT Ala56 with rigid-compulsive behavior [90]? Will they show increased sensory sensitivity, paralleling the association with sensory aversion [91]? Other questions relate to predicted behavioral changes due to altered SERT function. Will SERT Ala56 mice show altered response to pharmacological probes of the 5-HT system, including 5HT reuptake inhibitors and 5-HT receptor agonists? Might these mice help resolve the conundrum of replicated reductions in $5 \mathrm{HT}_{2}$ receptor density but utility of the $5 \mathrm{HT}_{2 \mathrm{a}}$ antagonist risperidone? Will they demonstrate changes in anxiety or stress reactivity that contrast with the SERT knockout mouse [51]?

Table 2 Genotype distribution of Gly56Ala offspring from heterozygous breeding pairs

\begin{tabular}{llll}
\hline & Gly/Gly & Gly/Ala & Ala/Ala \\
\hline Pups from 56Gly/Ala breeding & $18\left(20^{\circ}\right)$ & $42\left(41^{\circ}\right)$ & $21\left(20^{\circ}\right)$ \\
\hline
\end{tabular}

expectation from Hardy-Weinberg equilibrium

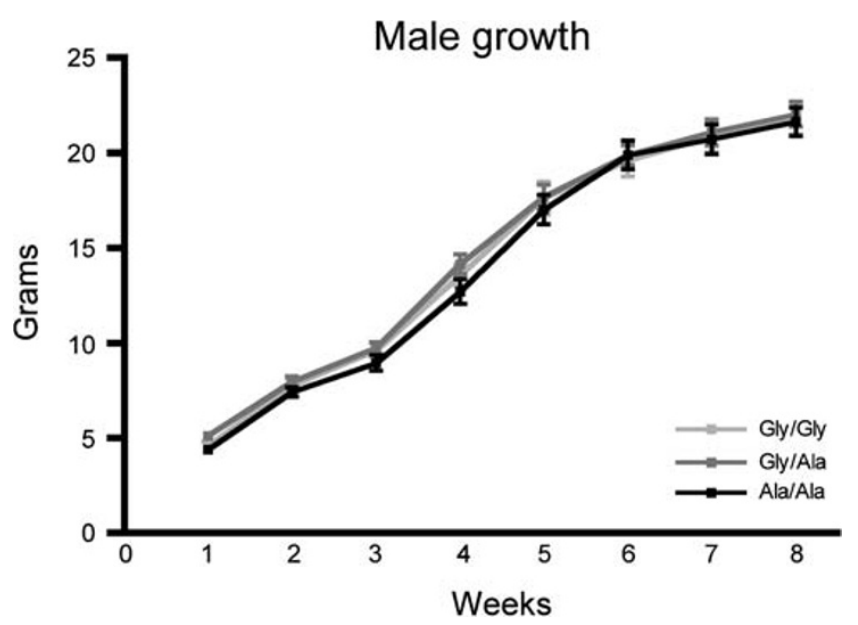

Fig. 6 Growth curves for wildtype and Ala56/Ala mice. Weight was recorded weekly from one week to eight weeks of life. Male growth is shown. Repeated measures ANOVA revealed a significant effect of week $(\mathrm{F}=996, p<0.001)$ but no significant effects of genotype $(F=$ $0.44, p=0.65)$ or genotype $\mathrm{x}$ week interaction $(F=0.47, p=0.95)$. Female growth also did not differ between genotypes (data not shown)

Our efforts to establish a behavioral readout of altered SERT function will rest on an understanding of underlying changes in brain development, synaptic function and signaling. Indeed, we believe this can help address the impact of SERT variation on brain architecture. Our initial focus will be targeted to brain regions that are altered in the SERT knockout mouse [91, 92] and/or those regions that may act as substrates for the behavioral alterations found in individuals with the SERT Ala56 variant. We then hope to advance from any observed changes in brain architecture to elucidate the underlying alterations in neurodevelopment that lead to these changes. Ultimately, our hope would be not just to characterize a brain and behavioral phenotype in the SERT Ala56 knock-in mouse, but also to capitalize on the model to develop novel methods of reversing the phenotype, either genetically or pharmacologically.

We have entered a new era in autism research with the transfer to animal models of functional human mutations linked to autism symptom domains. Time will tell if our efforts help unravel the complexities of autism, including the well known male bias, the long-standing biomarker of hyperserotonemia, and the seemingly independent trait domains that have been suggested to arise from distinct genetic mechanisms [93]. We have optimism that success in this venture can advance critical new models for the design of gene- or biomarker-based therapeutics.

Acknowledgements We gratefully acknowledge the input and support of Ana Carneiro, Chong-Bin Zhu, David Airey and investigators/staff of the Vanderbilt Silvio O. Conte Center for Neuroscience Research. We also appreciate the expert laboratory oversight provided by Jane Wright, Qiao Han, Angela Steele, Sarah Whitaker, and Kathryn Lindler. Research efforts were supported by 
NIH Award K08MH081066, an American Academy of Child and Adolescent Psychiatry Pilot Research Award and an Autism Speaks Pilot Award to J.V., a Scientist-Educator Award to B.J.T, a NARSAD Young Investigator Award to H.C.P. and NIH Awards NS049261 to J.S. S., DA07390 and MH078028 to R.D.B., and HD15052 for support of the Vanderbilt Transgenic Mouse/ESC Shared Resource.

\section{References}

1. Schain RJ, Freedman DX. Studies on 5-hydroxyindole metabolism in autistic and other mentally retarded children. J Pediatr. 1961;58:315-20.

2. Folk GE Jr, Long JP. Serotonin as a neurotransmitter: a review. Comp Biochem Physiol C. 1988;91:251-7.

3. Rapport MM, Green AA, Page IH. Serum vasoconstrictor, serotonin; isolation and characterization. J Biol Chem. 1948;176:1243-51.

4. Erspamer V, Asero B. Identification of enteramine, the specific hormone of the enterochromaffin cell system, as 5hydroxytryptamine. Nature. 1952;169:800-1.

5. Anderson GM, Feibel FC, Cohen DJ. Determination of serotonin in whole blood, platelet-rich plasma, platelet-poor plasma and plasma ultrafiltrate. Life Sci. 1987;40:1063-70.

6. Cook EH, Leventhal BL, Freedman DX. Free serotonin in plasma: Autistic children and their first-degree relatives. Biol Psychiatry. 1988;24:488-91.

7. Spivak B, Golubchik P, Mozes T, Vered Y, Nechmad A, Weizman A, et al. Low platelet-poor plasma levels of serotonin in adult autistic patients. Neuropsychobiology. 2004;50:157-60.

8. Kanner L. Autistic disturbances of affective contact. Nerv Child. $1943 ; 2: 217-50$.

9. Cook E, Leventhal B. The serotonin system in autism. Curr Opin Pediatr. 1996;8:348-54.

10. Mulder EJ, Anderson GM, Kema IP, de Bildt A, van Lang ND, den Boer JA, et al. Platelet serotonin levels in pervasive developmental disorders and mental retardation: diagnostic group differences, within-group distribution, and behavioral correlates. J Am Acad Child Adolesc Psychiatry. 2004;43:491-9.

11. Cook E, Arora R, Anderson G, Berry-Kravis E, Yan S-Y, Yeoh H, et al. Platelet serotonin studies in hyperserotonemic relatives of children with autistic disorder. Life Sci. 1993;52:2005-15.

12. Marazziti D, Muratori F, Cesari A, Masala I, Baroni S, Giannaccini G, et al. Increased density of the platelet serotonin transporter in autism. Pharmacopsychiatry. 2000;33:165-8.

13. Bursztejn C, Ferrari P, Dreux C, Braconnier A, Lancrenon S. Metabolisme de la serotonine dans l'autisme infantile. Encephalé. 1988;14:413-9.

14. Katsui T, Okuda M, Usuda S, Koizumi T. Kinetics of $3 \mathrm{H}-$ serotonin uptake by platelets in infantile autism and developmental language disorder (including five pairs of twins). J Autism Dev Disord. 1986;16:69-76.

15. Anderson GM, Minderaa RB, van Benthem PP, Volkmar FR, Cohen DJ. Platelet imipramine binding in autistic subjects. Psychiatry Res. 1984;11:133-41.

16. Rotman A, Caplan R, Szekely GA. Platelet uptake of serotonin in psychotic children. Psychopharmacology (Berl). 1980;67:245-8.

17. Sankar DVS. Uptake of 5-hydroxytryptamine by isolated platelets in childhood schizophrenia and autism. Neuropsychobiology. 1977;3:234-9.

18. Yuwiler A, Ritvo E, Geller E, Glousman R, Schneiderman G, Matsuno D. Uptake and efflux of serotonin from platelets of autistic and nonautistic children. J Autism Dev Disord. 1975;5:83-98.

19. Hranilovic D, Bujas-Petkovic Z, Tomicic M, Bordukalo-Niksic T, Blazevic S, Cicin-Sain L. Hyperserotonemia in autism: activity of 5HT-associated platelet proteins. J Neural Transm .2009
20. Cook EH Jr, Arora RC, Anderson GM, Berry-Kravis EM, Yan SY, Yeoh $\mathrm{HC}$, et al. Platelet serotonin studies in hyperserotonemic relatives of children with autistic disorder. Life Sci. 1993;52:2005-15.

21. Perry BD, Cook EH Jr, Leventhal BL, Wainwright MS, Freedman DX. Platelet 5-HT2 serotonin receptor binding sites in autistic children and their first-degree relatives. Biol Psychiatry. 1991;30:121-30.

22. McBride PA, Anderson GM, Hertzig ME, Sweeney JA, Kream J, Cohen DJ, et al. Serotonergic responsivity in male young adults with autistic disorder. Arch Gen Psychiatry. 1989;46:205-12.

23. Carneiro AM, Blakely RD. Serotonin, protein kinase C and HIC-5 associated redistribution of the platelet serotonin transporter. $\mathrm{J}$ Biol Chem. 2006.

24. Steiner JA, Carneiro AM, Blakely RD. Going with the flow: trafficking-dependent and -independent regulation of serotonin transport. Traffic. 2008;9:1393-402.

25. Carneiro AM, Blakely RD. Serotonin-, protein kinase C-, and Hic5 -associated redistribution of the platelet serotonin transporter. J Biol Chem. 2006;281:24769-80.

26. Carneiro AM, Cook EH, Murphy DL, Blakely RD. Interactions between integrin alphaIlbbeta3 and the serotonin transporter regulate serotonin transport and platelet aggregation in mice and humans. J Clin Invest. 2008;118:1544-52.

27. Janusonis S, Anderson GM, Shifrovich I, Rakic P. Ontogeny of brain and blood serotonin levels in 5-HT receptor knockout mice: potential relevance to the neurobiology of autism. J Neurochem. 2006;99:1019-31.

28. Yadav VK, Ryu JH, Suda N, Tanaka KF, Gingrich JA, Schutz G, et al. Lrp5 controls bone formation by inhibiting serotonin synthesis in the duodenum. Cell. 2008;135:825-37.

29. Piven J, Tsai G, Nehme E, Coyle JT, Folstein SE. Platelet serotonin, a possible marker for familial autism. J Autism Dev Disord. 1991;21:51-9.

30. Abney M, McPeek MS, Ober C. Broad and narrow heritabilities of quantitative traits in a founder population. Am J Hum Genet. 2001;68:1302-7.

31. Meltzer HY, Arora RC. Genetic control of serotonin uptake in blood platelets: a twin study. Psychiatry Res. 1988;24:263-9.

32. Weiss LA, Veenstra-VanderWeele J, Abney M, Newman DL, Kim S-J, Dytch H, McPeek MS, Cheng S, Cook EH, Jr., Ober C. Genome-wide association study identifies ITGB3 as a QTL for whole blood serotonin. European Journal of Human Genetics 2004; advance online publication.

33. Weiss LA, Abney M, Cook EH Jr, Ober C. Sex-specific genetic architecture of whole blood serotonin levels. Am J Hum Genet. 2005;76:33-41.

34. Weiss LA, Ober C, Cook EH Jr. ITGB3 shows genetic and expression interaction with SLC6A4. Hum Genet. 2006;120:93100.

35. Coutinho AM, Sousa I, Martins M, Correia C, Morgadinho T, Bento C, et al. Evidence for epistasis between SLC6A4 and ITGB3 in autism etiology and in the determination of platelet serotonin levels. Hum Genet. 2007;121:243-56.

36. Mei H, Cuccaro ML, Martin ER. Multifactor dimensionality reduction-phenomics: a novel method to capture genetic heterogeneity with use of phenotypic variables. Am J Hum Genet. 2007;81:1251-61.

37. Chugani DC, Muzik O, Behen M, Rothermel R, Janisse JJ, Lee $\mathrm{J}$, et al. Developmental changes in brain serotonin synthesis capacity in autistic and nonautistic children. Ann Neurol. 1999;45:287-95.

38. Murphy DG, Daly E, Schmitz N, Toal F, Murphy K, Curran S, et al. Cortical serotonin 5-HT2A receptor binding and social communication in adults with Asperger's syndrome: an in vivo SPECT study. Am J Psychiatry. 2006;163:934-6. 
39. Goldberg J, Anderson GM, Zwaigenbaum L, Hall GB, Nahmias C, Thompson A, et al. Cortical serotonin type-2 receptor density in parents of children with autism spectrum disorders. J Autism Dev Disord. 2009;39:97-104.

40. Antzoulatos E, Gibbs T, Pugh J, Bauman M, Kemper T, Blatt G. Serotonin receptors in the autistic brain. In: Int Mtg for Autism Res: Boston; 2005 p. P1A.2.1.

41. McDougle C, Naylor S, Cohen D, Aghajanian G, Heninger G, Price L. Effects of tryptophan depletion in drug-free adults with autistic disorder. Arch Gen Psychiatry. 1996;53:993-1000.

42. Hollander E, Phillips A, Chaplin W, Zagursky K, Novotny S, Wasserman S, et al. A placebo controlled crossover trial of liquid fluoxetine on repetitive behaviors in childhood and adolescent autism. Neuropsychopharmacology. 2005;30:582-9.

43. Gordon C, State R, Nelson J, Hamburger S, Rapoport J. A doubleblind comparison of clomipramine, desipramine, and placebo in the treatment of autistic disorder. Arch Gen Psychiatry. 1993;50:441-7.

44. McCracken JT, McGough J, Shah B, Cronin P, Hong D, Aman $\mathrm{MG}$, et al. Risperidone in children with autism and serious behavioral problems. N Engl J Med. 2002;347:314-21.

45. McDougle CJ, Scahill L, Aman MG, McCracken JT, Tierney E, Davies M, et al. Risperidone for the core symptom domains of autism: results from the study by the autism network of the research units on pediatric psychopharmacology. Am J Psychiatry. 2005;162:1142-8.

46. International Molecular Genetic Study of Autism Consortium. A genome wide screen for autism: Strong evidence for linkage to chromosomes 2q, 7q and 16p. Am J Hum Genet. 2001;69:570-81.

47. Yonan AL, Alarcon M, Cheng R, Magnusson PK, Spence SJ, Palmer AA, et al. A genomewide screen of 345 families for autism-susceptibility loci. Am J Hum Genet. 2003;73:886-97.

48. Stone JL, Merriman B, Cantor RM, Yonan AL, Gilliam TC, Geschwind DH, et al. Evidence for sex-specific risk alleles in autism spectrum disorder. Am J Hum Genet. 2004;75:1117-23.

49. Sutcliffe JS, Delahanty RJ, Prasad HC, McCauley JL, Han Q, Jiang L, et al. Allelic Heterogeneity at the Serotonin Transporter Locus (SLC6A4) Confers Susceptibility to Autism and RigidCompulsive Behaviors. Am J Hum Genet. 2005;77:265-79.

50. Cantor RM, Kono N, Duvall JA, Alvarez-Retuerto A, Stone JL, Alarcon M, Nelson SF, Geschwind DH. Replication of Autism Linkage: Fine-Mapping Peak at 17q21. Am J Hum Genet. 2005;76.

51. Murphy DL, Lesch KP. Targeting the murine serotonin transporter: insights into human neurobiology. Nat Rev Neurosci. 2008;9:85-96.

52. Lesch K-P, Bengel D, Heils A, Sabol SZ, Greenberg BD, Petri S, et al. Association of anxiety-related traits with a polymorphism in the serotonin transporter gene regulatory region. Science. 1996;274:1527-31.

53. Cook EH Jr, Courchesne R, Lord C, Cox NJ, Yan S, Lincoln A, et al. Evidence of linkage between the serotonin transporter and autistic disorder. Mol Psychiatry. 1997;2:247-50.

54. Huang CH, Santangelo SL. Autism and serotonin transporter gene polymorphisms: a systematic review and meta-analysis. Am J Med Genet B Neuropsychiatr Genet. 2008;147B:903-13.

55. Yonan AL, Palmer AA, Gilliam TC. Hardy-Weinberg disequilibrium identified genotyping error of the serotonin transporter (SLC6A4) promoter polymorphism. Psychiatr Genet. 2006;16:31-4.

56. Wendland JR, Moya PR, Kruse MR, Ren-Patterson RF, Jensen $\mathrm{CL}$, Timpano KR, et al. A novel, putative gain-of-function haplotype at SLC6A4 associates with obsessive-compulsive disorder. Hum Mol Genet. 2008;17:717-23.

57. Hu XZ, Lipsky RH, Zhu G, Akhtar LA, Taubman J, Greenberg $\mathrm{BD}$, et al. Serotonin transporter promoter gain-of-function genotypes are linked to obsessive-compulsive disorder. Am J Hum Genet. 2006;78:815-26.

58. MacKenzie A, Quinn J. A serotonin transporter gene intron 2 polymorphic region, correlated with affective disorders, has alleledependent differential enhancer- like properties in the mouse embryo. Proc Natl Acad Sci U S A. 1999;96:15251-5.

59. Kim S-J, Cox N, Courchesne R, Lord C, Corsello C, Akshoomoff $\mathrm{N}$, et al. Transmission disequilibrium mapping in the serotonin transporter gene $(S L C 6 A 4)$ region in autistic disorder. Mol Psychiatry. 2002;7:278-88.

60. McCauley JL, Olson LM, Dowd M, Amin T, Steele A, Blakely $\mathrm{RD}$, et al. Linkage and association analysis at the serotonin transporter (SLC6A4) locus in a rigid-compulsive subset of autism. Am J Med Genet B Neuropsychiatr Genet. 2004;127:104-12.

61. Cross S, Kim SJ, Weiss LA, Delahanty RJ, Sutcliffe JS, Leventhal $\mathrm{BL}$, et al. Molecular genetics of the platelet serotonin system in first-degree relatives of patients with autism. Neuropsychopharmacology. 2008;33:353-60.

62. Mulder EJ, Anderson GM, Kema IP, Brugman AM, Ketelaars CE, de Bildt A, van Lang ND, den Boer JA, Minderaa RB. Serotonin transporter intron 2 polymorphism associated with rigidcompulsive behaviors in Dutch individuals with pervasive developmental disorder. Am J Med Genet B Neuropsychiatr Genet. 2005.

63. Brune CW, Kim SJ, Salt J, Leventhal BL, Lord C, Cook EH Jr. 5HTTLPR Genotype-Specific Phenotype in Children and Adolescents With Autism. Am J Psychiatry. 2006;163:2148-56.

64. Coutinho AM, Oliveira G, Morgadinho T, Fesel C, Macedo TR, Bento $\mathrm{C}$, et al. Variants of the serotonin transporter gene (SLC6A4) significantly contribute to hyperserotonemia in autism. Mol Psychiatry. 2004;9:264-71.

65. Wassink TH, Hazlett HC, Epping EA, Arndt S, Dager SR, Schellenberg GD, et al. Cerebral cortical gray matter overgrowth and functional variation of the serotonin transporter gene in autism. Arch Gen Psychiatry. 2007;64:709-17.

66. Van Esch H, Bauters M, Ignatius J, Jansen M, Raynaud M, Hollanders K, et al. Duplication of the MECP2 region is a frequent cause of severe mental retardation and progressive neurological symptoms in males. Am J Hum Genet. 2005;77:442-53.

67. Dickel DE, Veenstra-VanderWeele J, Bivens NC, Wu X, Fischer DJ, Van Etten-Lee M, et al. Association studies of serotonin system candidate genes in early-onset obsessive-compulsive disorder. Biol Psychiatry. 2007;61:322-9.

68. Page DT, Kuti OJ, Prestia C, Sur M. Haploinsufficiency for Pten and Serotonin transporter cooperatively influences brain size and social behavior. Proc Natl Acad Sci U S A. 2009;106:1989-94.

69. Haase J, Killian AM, Magnani F, Williams C. Regulation of the serotonin transporter by interacting proteins. Biochem Soc Trans. 2001;29:722-8.

70. Carneiro A, Ingram SL, Beaulieu J-M, Sweeney A, Amara SG, Thomas SM, et al. The multiple LIM domain-containing adaptor protein Hic-5 synaptically colocalizes and interacts with the dopamine transporter. J Neurosci. 2002;22:7045-54.

71. Carneiro AM, Blakely RD. Serotonin, protein kinase C and HIC-5 associated redistribution of the platelet serotonin transporter. $\mathrm{J}$ Biol Chem 2006; published online June 27.

72. Prasad HC, Zhu CB, McCauley JL, Samuvel DJ, Ramamoorthy $\mathrm{S}$, Shelton RC, et al. Human serotonin transporter variants display altered sensitivity to protein kinase $\mathrm{G}$ and $\mathrm{p} 38$ mitogenactivated protein kinase. Proc Natl Acad Sci U S A. 2005; 102:11545-50.

73. Sakurai T, Reichert J, Hoffman EJ, Cai G, Jones HB, Faham M, et al. A large-scale screen for coding variants in SERT/SLC6A4 in autism spectrum disorders. Autism Res. 2008;1:251-7. 
74. Wendland JR, Kruse MR, Murphy DL. Functional SLITRK1 var321, varCDfs and SLC6A4 G56A variants and susceptibility to obsessive-compulsive disorder. Mol Psychiatry. 2006;11:802-4.

75. Glatt C, DeYoung J, Delgado S, Service S, Giacomini K, Edwards $\mathrm{R}$, et al. Screening a large reference sample to identify very low frequency sequence variants: comparisons between two genes. Nat Genet. 2001;27:435-8.

76. Ramamoorthy S, Bauman AL, Moore KR, Han H, Yang-Feng T, Chang AS, et al. Antidepressant- and cocaine-sensitive human serotonin transporter: molecular cloning, expression, and chromosomal localization. Proc Natl Acad Sci U S A. 1993;90:2542-6.

77. Ozaki N, Goldman D, Kaye W, Plotnikov K, Greenberg B, Rudnick $\mathrm{G}$, et al. A missense mutation in the serotonin transporter is associated with a complex neuropsychiatric phenotype. Mol Psychiatry. 2003;8:933-6.

78. Delorme R, Betancur C, Wagner M, Krebs MO, Gorwood P, Pearl P, Nygren G, Durand CM, Buhtz F, Pickering P, Melke J, Ruhrmann S, Anckarsater H, Chabane N, Kipman A, Reck C, Millet B, Roy I, Mouren-Simeoni MC, Maier W, Rastam M, Gillberg C, Leboyer M, Bourgeron T. Support for the association between the rare functional variant $1425 \mathrm{~V}$ of the serotonin transporter gene and susceptibility to obsessive compulsive disorder. Mol Psychiatry. 2005.

79. Prasad HC, Steiner JA, Sutcliffe JS, Blakely RD. Enhanced activity of human serotonin transporter variants associated with autism. Philos Trans R Soc Lond B Biol Sci. 2009;364:163-73.

80. Zhu CB, Hewlett WA, Feoktistov I, Biaggioni I, Blakely RD. Adenosine receptor, protein kinase $\mathrm{G}$, and p38 mitogen-activated protein kinase-dependent up-regulation of serotonin transporters involves both transporter trafficking and activation. Mol Pharmacol. 2004;65:1462-74.

81. Bauman AL, Apparsundaram S, Ramamoorthy S, Wadzinski BE, Vaughan RA, Blakely RD. Cocaine and antidepressant-sensitive biogenic amine transporters exist in regulated complexes with protein phosphatase 2A. J Neurosci. 2000;20:7571-8.

82. Bengel D, Murphy DL, Andrews AM, Wichems CH, Feltner D, Heils A, et al. Altered brain serotonin homeostasis and locomotor insensitivity to 3, 4- methylenedioxymethamphetamine ("Ecstasy") in serotonin transporter- deficient mice. Mol Pharmacol. 1998;53:649-55.

83. Moy SS, Nadler JJ, Young NB, Nonneman RJ, Grossman AW, Murphy DL, D'Ercole AJ, Crawley JN, Magnuson TR, Lauder
JM. Social Approach in Genetically-Engineered Mouse Lines Relevant to Autism. Genes Brain Behav. 2008.

84. Jennings KA, Loder MK, Sheward WJ, Pei Q, Deacon RM, Benson MA, et al. Increased expression of the 5-HT transporter confers a low-anxiety phenotype linked to decreased 5-HT transmission. J Neurosci. 2006;26:8955-64.

85. Jennings KA, Sheward WJ, Harmar AJ, Sharp T. Evidence that genetic variation in 5-HT transporter expression is linked to changes in 5-HT2A receptor function. Neuropharmacology. 2008;54:776-83.

86. Qu Y, Villacreses N, Murphy DL, Rapoport SI. 5-HT2A/2C receptor signaling via phospholipase $\mathrm{A} 2$ and arachidonic acid is attenuated in mice lacking the serotonin reuptake transporter. Psychopharmacology (Berl). 2005;180:12-20.

87. O'Gorman S, Dagenais NA, Qian M, Marchuk Y. Protamine-Cre recombinase transgenes efficiently recombine target sequences in the male germ line of mice, but not in embryonic stem cells. Proc Natl Acad Sci U S A. 1997;94:14602-7.

88. Crawley JN. Mouse behavioral assays relevant to the symptoms of autism. Brain Pathol. 2007;17:448-59.

89. Moy SS, Nadler JJ, Perez A, Barbaro RP, Johns JM, Magnuson TR, et al. Sociability and preference for social novelty in five inbred strains: an approach to assess autistic-like behavior in mice. Genes Brain Behav. 2004;3:287-302.

90. Moy SS, Nadler JJ, Poe MD, Nonneman RJ, Young NB, Koller BH, et al. Development of a mouse test for repetitive, restricted behaviors: relevance to autism. Behav Brain Res. 2008;188:178-94.

91. Esaki T, Cook M, Shimoji K, Murphy DL, Sokoloff L, Holmes A. Developmental disruption of serotonin transporter function impairs cerebral responses to whisker stimulation in mice. Proc Natl Acad Sci U S A. 2005;102:5582-7.

92. Wellman CL, Izquierdo A, Garrett JE, Martin KP, Carroll J, Millstein R, et al. Impaired stress-coping and fear extinction and abnormal corticolimbic morphology in serotonin transporter knock-out mice. J Neurosci. 2007;27:684-91.

93. Hus V, Pickles A, Cook EH Jr, Risi S, Lord C. Using the autism diagnostic interview-revised to increase phenotypic homogeneity in genetic studies of autism. Biol Psychiatry. 2007;61:438-48.

94. Zhang YW, Gesmonde J, Ramamoorthy S, Rudnick G. Serotonin transporter phosphorylation by cGMP-dependent protein kinase is altered by a mutation associated with obsessive compulsive disorder. J Neurosci. 2007;27:10878-86. 